\title{
Experimental and theoretical study on the structure-property relationship of novel 1-aryl-3-methylsuccinimides
}

\author{
Nebojša R. Banjac ${ }^{a}$, Bojan Đ. Božić ${ }^{\text {b, * }}$, Jelena M. Mirković ${ }^{b}$, Vesna D. Vitnik ${ }^{c}$, \\ Željko J. Vitnik ${ }^{\mathrm{c}}$, Nataša V. Valentić ${ }^{\mathrm{b}}$, Gordana S. Ušćumlić ${ }^{\mathrm{b}}$ \\ ${ }^{a}$ Faculty of Agriculture, Food Technology and Biochemistry, University of Belgrade, Nemanjina 6, 11080, Belgrade, Zemun, Serbia \\ ${ }^{\mathrm{b}}$ Department of Organic Chemistry, Faculty of Technology and Metallurgy, University of Belgrade, Karnegijeva 4, P.O. Box 3503, 11120, Belgrade, Serbia \\ ${ }^{\mathrm{c}}$ Department of Chemistry, ICTM, University of Belgrade, Studentski trg 12-16, 11000, Belgrade, Serbia
}

\section{A R T I C L E I N F O}

\section{Article history:}

Received 22 June 2016

Received in revised form 28 September 2016

Accepted 29 September 2016

Available online 30 September 2016

\section{Keywords:}

Succinimide

Absorption spectra

Solvent effect

Substituent effect

Quantum chemical calculation

\begin{abstract}
A B S T R A C T
A series of ten 1-aryl-3-methylsuccinimides was synthesized and their solvatochromic properties were studied in a set of fifteen binary solvent mixtures. The solute-solvent interactions were analyzed on the basis of the linear solvation energy relationship (LSER) concept proposed by Kamlet and Taft. The electronic effect of the substituents on the UV-Vis absorption and NMR spectra was analyzed using the simple Hammett equation. Moreover, the B3LYP, CAM-B3LYP, and M06-2X functionals using the 6 $-311 G(d, p)$ basic set have been assessed in light of the position of experimental absorption maxima obtained for these compounds. The integration grid effects have also been evaluated. An interpretation of the substituent-effect transmission through the molecular skeleton and the nature of the HOMO and LUMO orbitals based on quantum-chemical calculations is given. The values of partial atomic charges from the atomic polar tenzors (APT), natural population analysis (NBO), and charges fit to the electrostatic potential using the B3LYP, CAM-B3LYP, and M06-2X methods are produced and correlated with different experimental properties. In order to estimate the chemical activity of the molecule, the molecular electrostatic potential (MEP) surface map is calculated for the optimized geometry of 1-phenyl-3methylsuccinimide.
\end{abstract}

๑) 2016 Elsevier B.V. All rights reserved.

\section{Introduction}

Five-membered heterocycles with nitrogen in their structure are widely used in different fields of science such as medicine, biology, and chemistry. Succinimides (pyrrolidine-2,5-diones) and hydantoins (imidazolidine-2,4-diones) have been promising candidates for anticonvulsive agents since they contain necessary structural features responsible for this activity. This comprises a cyclic imide, one or more carbonyl groups, and a lipophilic part of the molecule consisting of phenyl or alkyl groups related to heterocyclic rings in certain relative orientations [1-6]. Additionally, it has been experimentally established that succinimides possess anticonvulsive activity since they are efficient against the maximal electroshock (MES) and subcutaneous pentylenetetrazole (scPTZ) screens set standards for drug testing in early phases [7-9].

Correlation studies between chromatographic data and the

\footnotetext{
* Corresponding author.

E-mail address: bbozic@tmf.bg.ac.rs (B.Đ. Božić).
}

selected structural features described by ADMET parameters (refers to absorption, distribution, metabolism, elimination, and toxicity in pharmacokinetics) of 1-aryl-3-phenyl-, 1-aryl-3,3-diphenyl- and 1aryl-3-methylsucccinimides have been reported previously using computational medicinal chemistry methods $[2,10]$. According to these results, the investigated succinimides of the most promising pharmacokinetics have been selected for further pharmacodynamic drug development. It has been demonstrated that the affinity of a particular molecule, defined as a potential anticonvulsive drug, to a specific receptor highly depends on the interactions of the molecule with its surrounding space [11]. A key feature of the molecules responsible for the transport through biological systems is its lipophilicity. According to the literature, most active centralnervous system drugs have optimum lipophilicity, defined as the logarithm of the 1-octanol/water partition coefficient $(\log P)$, close to $2[12,13]$. An ability to transport through biological membranes by passive diffusion is another important property of the molecules, necessary for the in biological activity. This process involves a series of partitioning steps, in combination with diffusion through 
several regions, i.e., partitioning between aqueous intra- and extracellular media and phospholipid membranes [2]. Therefore, for a further study of succinimides as potential anticonvulsant drugs, their solvatochromic properties need to be taken into consideration.

The purpose of this research is the application of the solvatochromic comparison method for quantification and correlation of multiple solvent effects with properties and interactions of the investigated succinimides which have potential pharmaceutical applications. To the best of our knowledge, the structural spectroscopic and solvatochromic properties of 1-aryl-3methylpyrrolidine-2,5-diones have not been thoroughly studied. In this work, ten 1-aryl-3-methylpyrrolidine-2,5-diones (Scheme 1) have been synthesized and their solvatochromism has been studied in a set of fifteen binary solvent mixtures. The effects of specific and non-specific interactions between succinimide and solvent molecules on UV absorption maxima have been interpreted by the linear solvation energy relationship (LSER) concept using the Kamlet-Taft equation [14]. Moreover, the effects of substituents on the UV absorption frequencies and ${ }^{13} \mathrm{C}$ NMR chemical shifts have been analyzed by a linear free energy relationship (LFER) model, using the simple Hammett equation [15]. In order to support structural and solvatochromic properties of the investigated succinimides, density functional theory (DFT/6-311G(d,p)) calculations have been carried out. The UV spectroscopic studies, as well as HOMO and LUMO analysis, have been used to elucidate the intramolecular charge transfer (ICT). Furthermore, the molecular electrostatic potential (MEP) surface map has been calculated for the optimized geometry of the investigated succinimides in order to evaluate the chemical activity of these molecules.

\section{Results and discussion}

\subsection{Spectroscopic analysis}

\subsubsection{UV-spectroscopic measurements}

The UV absorption spectra of the 1-aryl-3-methylpyrrolidine2,5-diones 1-10 have been recorded in three pure solvents and selected binary solvent mixtures in the range of $200-400 \mathrm{~nm}$. Wavenumbers of the absorption maxima measured in different solvents and their mixtures are given in Table 1 . Table 1 shows that the UV absorption wavenumbers strongly depend on the nature of the substituent, and that they are less affected by solvent properties. All substituents cause bathochromic band shifts relative to the unsubstituted compound 4.

The weakly electron-donating $-\mathrm{CH}_{3}$ group induces the smallest positive solvatochromism, while the strongly electronwithdrawing $-\mathrm{NO}_{2}$ group exhibits the largest solvent-induced bathochromic shift. UV absorption band shifts (Table 1) are ascribed to different $\pi \rightarrow \pi^{*}$ transitions involving the $\pi$-electron

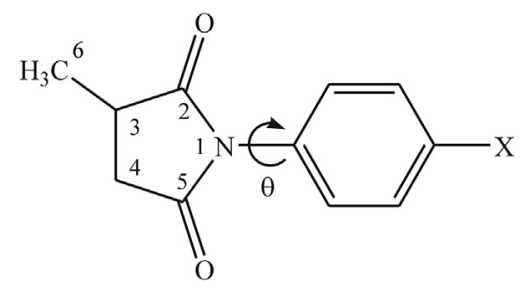

\begin{tabular}{l|cccccccccc} 
No. & $\mathbf{1}$ & $\mathbf{2}$ & $\mathbf{3}$ & $\mathbf{4}$ & $\mathbf{5}$ & $\mathbf{6}$ & $\mathbf{7}$ & $\mathbf{8}$ & $\mathbf{9}$ & $\mathbf{1 0}$ \\
\hline $\mathrm{X}$ & $\mathrm{OH}$ & $\mathrm{OMe}$ & $\mathrm{Me}$ & $\mathrm{H}$ & $\mathrm{Cl}$ & $\mathrm{Br}$ & $\mathrm{I}$ & $\mathrm{COOH}$ & $\mathrm{COMe}$ & $\mathrm{NO}_{2}$
\end{tabular}

Scheme 1. Molecular structure of the 1-aryl-3-methylpyrrolidine-2,5-diones 1-10 with the atoms and torsion angle labeled. system of the investigated compounds (Fig. 1 ). The $\pi$-delocalization is mainly a result of the $\pi$-electron density transmission from the phenyl ring, caused by electronic effects of the substituents in 4position, to the carbonyl groups of the succinimide unit. The bathochromic band shifts observed for all compounds support the fact that a $\pi \rightarrow \pi^{*}$ transition is responsible for UV absorption. Moreover, the planarity of the molecule is the feature which significantly affects transmission of the resonance effect through the molecule and therefore influences the contribution of the $\pi$ delocalization to the UV absorption of each compound.

The strength of the specific and nonspecific interactions between the succinimide and solvent molecules changes upon excitation as a consequence of the different stabilization in the ground and excited states. In all solvents and binary mixtures, for compounds 1-10, a small bathochromic shifts have been observed as a result of the solvent-solute interactions. This is characteristic for molecules with low dipolarity in the ground state, as electronic transitions in these molecules are associated with an intramolecular electron transfer and where delocalization of electrons is possible between nitrogen and oxygen, i.e. overlapping of $\pi$-electrons of carbonyl groups and a lone pair of amide nitrogen (Fig. 1).

\subsubsection{Solvent effects on the electronic spectra (LSER analysis)}

In order to explain the solvatochromism of 1-10, their UV absorption data have been correlated with the simplified Kamlet-Taft solvatochromic equation [16]:

$v=v_{0}+\mathrm{s} \pi^{*}+\mathrm{a} \alpha$

where $\pi^{*}$ is an index of the solvent dipolarity/polarizability, $\alpha$ is a measure of the solvent hydrogen-bonding donor (HBD) acidity, and $\nu_{0}$ is the absorption value in cyclohexane as reference solvent [14]. The relative susceptibilities of absorption frequencies to the corresponding solvent parameters are expressed through the regression coefficients $s$ and a (Eq. (1)). The solvent hydrogen-bond basicity parameter $\beta$ is excluded from the correlations due to its insignificant impact. Kamlet-Taft's solvatochromic comparison model is widely used for the quantitative interpretation of specific and nonspecific solvent effects on UV-Vis absorption spectra since this model supposes attractive interactions between the investigated solute and its surrounding and enables evaluation of the capability of the solutes to form hydrogen bonds with the solvent. The correlations of the absorption wavenumbers $\nu_{\max }$ have been achieved by multiple linear regression analysis. The results of the correlation analysis are presented in Table 2 and the percentage contributions of each interaction in overall solvation are given in Table 3 . The independent coefficients $\nu_{0}$, s, and a (Table 2) are fitted at the $95 \%$ confidence level (see Table 4 ).

The absorption wavenumbers $\left(\nu_{\max }\right)$ of the 1-aryl-3methylsuccinimides 1-10 measured in pure solvents and in selected binary solvent mixtures show a satisfactory correlation with the solvent parametars $\pi^{*}$ and $\alpha$ (Table 2). The results presented in Table 2 show that in all cases (excluding compounds $\mathbf{3}, \mathbf{5}$, and 8) the absolute value of $a$ is greater than $s$, which means that the solvent HBD acidity plays a more important role on their solvatochromism than non-specific (solvent dipolarity/polarizability) interactions. For the excluded compounds $(\mathbf{3}, \mathbf{5}$, and $\mathbf{8})$, the solvent dipolarity/polarizability has a slightly higher significance than HBD, while in all cases the solvent hydrogen-bond acceptor basicity has no influence on the solvatochromism of 1-10.

From the analysis of the absorption wavenumbers according to the Kamlet-Taft Eq. (1), it has been found that the negative signs of $s$ (excluding 4, 5, 6, and 8) and $a$ (excluding 4 and 8) for all 1-aryl-3methylsuccinimides (Table 2) indicate a bathochromic band shift with increasing solvent dipolarity/polarizability and solvent 
Table 1

Long-wavelength UV absorption maxima of 1-aryl-3-methylpyrrolidine-2,5-diones 1-10.

\begin{tabular}{|c|c|c|c|c|c|c|c|c|c|c|}
\hline \multirow[t]{2}{*}{ Solvent/Comp. No. } & \multicolumn{10}{|c|}{$v_{\max } \times 10^{-3} / \mathrm{cm}^{-1}$} \\
\hline & 1 & 2 & 3 & 4 & 5 & 6 & 7 & 8 & 9 & 10 \\
\hline Methanol & 43.71 & 43.63 & 45.41 & 46.99 & 44.48 & 43.71 & 42.05 & 41.81 & 39.49 & 36.36 \\
\hline Methanol/ $\mathrm{H}_{2} \mathrm{O}(80: 20)^{\mathrm{a}}$ & 42.59 & 42.64 & 44.52 & 46.79 & 44.40 & 43.40 & 40.72 & 40.36 & 38.67 & 35.60 \\
\hline Methanol/ $\mathrm{H}_{2} \mathrm{O}(60: 40)$ & 42.23 & 42.27 & 44.27 & 46.71 & 44.27 & 43.90 & 40.75 & 41.25 & 38.55 & 36.21 \\
\hline Methanol/ $\mathrm{H}_{2} \mathrm{O}(40: 60)$ & 42.83 & 42.63 & 44.19 & 46.75 & 44.17 & 43.46 & 40.77 & 40.82 & 39.06 & 36.15 \\
\hline Ethanol & 43.92 & 43.46 & 45.52 & 46.25 & 44.66 & 43.22 & 41.79 & 42.27 & 39.90 & 36.18 \\
\hline Ethanol/ $\mathrm{H}_{2} \mathrm{O}(80: 20)$ & 43.74 & 43.38 & 45.48 & 46.21 & 44.48 & 43.80 & 42.09 & 42.48 & 39.59 & 36.55 \\
\hline Ethanol $/ \mathrm{H}_{2} \mathrm{O}(60: 40)$ & 44.09 & 43.98 & 45.54 & 45.91 & 45.23 & 44.27 & 41.81 & 43.07 & 40.97 & 36.23 \\
\hline Ethanol/ $\mathrm{H}_{2} \mathrm{O}(40: 60)$ & 43.80 & 43.82 & 45.54 & 46.08 & 45.60 & 43.96 & 42.25 & 43.37 & 41.41 & 36.09 \\
\hline 2-Propanol & 42.92 & 43.48 & 43.94 & 45.87 & 44.54 & 43.50 & 41.89 & 40.95 & 42.03 & 36.47 \\
\hline 2-Propanol/ $\mathrm{H}_{2} \mathrm{O}(80: 20)$ & 44.01 & 44.29 & 45.37 & 46.06 & 44.70 & 43.69 & 42.00 & 41.82 & 39.68 & 36.67 \\
\hline 2-Propanol/ $/ \mathrm{H}_{2} \mathrm{O}(60: 40)$ & 43.78 & 43.74 & 45.50 & 45.91 & 44.76 & 44.35 & 42.23 & 41.65 & 40.13 & 36.59 \\
\hline 2-Propanol/ $\mathrm{H}_{2} \mathrm{O}(40: 60)$ & 44.01 & 43.92 & 45.31 & 46.23 & 44.80 & 44.21 & 42.18 & 42.11 & 39.98 & 36.51 \\
\hline 2-Propanol/Ethanol(80:20) & 43.18 & 42.84 & 45.25 & 46.23 & 44.68 & 43.46 & 41.82 & 41.27 & 40.40 & 36.42 \\
\hline 2-Propanol/Ethanol(60:40) & 44.01 & 43.67 & 45.37 & 46.02 & 44.84 & 43.86 & 41.96 & 41.41 & 39.65 & 37.04 \\
\hline 2-Propanol/Ethanol(40:60) & 43.73 & 43.57 & 45.29 & 45.87 & 44.44 & 43.73 & 41.91 & 41.24 & 39.25 & 35.69 \\
\hline 2-Propanol/Methanol (80:20) & 43.44 & 43.54 & 45.17 & 45.66 & 44.35 & 43.73 & 42.02 & 41.51 & 39.06 & 36.35 \\
\hline 2-Propanol/Methanol (60:40) & 43.59 & 43.63 & 45.33 & 45.96 & 44.58 & 43.84 & 42.05 & 41.46 & 39.26 & 36.64 \\
\hline 2-Propanol/Methanol (40:60) & 43.67 & 43.73 & 45.43 & 45.83 & 44.74 & 43.92 & 42.02 & 41.55 & 39.51 & 36.31 \\
\hline
\end{tabular}

a Percentage of binary solvent mixtures in Vol - \%.<smiles>[X]c1ccc(N2C(=O)CC(C)C2=O)cc1</smiles>

Fig. 1. Mesomeric structures of 1-aryl-3-methylsuccinimides.

hydrogen-bond donor acidity. This suggests better stabilization of the electron in excited state by solvent molecules relative to the ground state.

Based on these results, it can be concluded that interactions of solvent with the investigated compounds are very complex and that the nature of the substituents have a strong influence on the UV absorption maxima. This phenomenon is mainly caused by the differences in the conjugational or migrating abilities of the electron lone pair on succinimide nitrogen.
2.1.3. Effects of substituents on the UV and NMR spectra of 1-10 (LFER analysis)

In order to gain insight into factors affecting the position of the UV absorption maxima and the transmission of the electronic effects, the absorption wavenumbers of the 1-aryl-3methylsuccinimides 1-10 have been correlated with Hammett substituent constants, $\sigma_{\mathrm{p}}$ and $\sigma_{\mathrm{p}}^{+}$, according to Hammett Equation [15]: 
Table 2

Regression fits to the solvatochromic parameters of Eq. (1).

\begin{tabular}{|c|c|c|c|c|c|c|c|c|}
\hline No. & Substituent & $\nu_{0} \times 10^{-3} / \mathrm{cm}^{-1}$ & $\mathrm{~s} \times 10^{-3} / \mathrm{cm}^{-1}$ & $\mathrm{a} \times 10^{-3} / \mathrm{cm}^{-1}$ & $\mathrm{R}^{\mathrm{a}}$ & $s^{b}$ & $\mathrm{~F}^{\mathrm{c}}$ & $\mathrm{n}^{\mathrm{d}}$ \\
\hline 1 & $4-\mathrm{OH}$ & $47.87( \pm 0.827)$ & $-2.37( \pm 0.810)$ & $-3.12( \pm 1.004)$ & 0.9122 & 0.299 & 17 & 10 \\
\hline 2 & $4-\mathrm{OCH}_{3}$ & $46.81( \pm 0.621)$ & $-1.67( \pm 0.628)$ & $-2.71( \pm 0.827)$ & 0.9256 & 0.226 & 21 & 10 \\
\hline 3 & $4-\mathrm{CH}_{3}$ & $49.18( \pm 0.599)$ & $-2.75( \pm 0.515)$ & $-2.41( \pm 0.635)$ & 0.9451 & 0.199 & 30 & 10 \\
\hline 4 & $\mathrm{H}$ & $42.77( \pm 0.451)$ & $0.919( \pm 0.397)$ & $3.08( \pm 0.456)$ & 0.9338 & 0.173 & 31 & 12 \\
\hline 5 & $4-\mathrm{Cl}$ & $44.78( \pm 0.447)$ & $4.43( \pm 0.651)$ & $-3.15( \pm 0.691)$ & 0.9320 & 0.166 & 23 & 10 \\
\hline 6 & $4-\mathrm{Br}$ & $44.62( \pm 0.347)$ & $2.81( \pm 0.396)$ & $-2.87( \pm 0.399)$ & 0.9550 & 0.122 & 36 & 10 \\
\hline 7 & $4-\mathrm{I}$ & $48.17( \pm 0.887)$ & $-1.81( \pm 0.612)$ & $-5.55( \pm 0.885)$ & 0.9330 & 0.252 & 27 & 11 \\
\hline 8 & $4-\mathrm{COOH}$ & $35.50( \pm 0.987)$ & $4.53( \pm 0.846)$ & $4.38( \pm 1.180)$ & 0.9224 & 0.309 & 29 & 13 \\
\hline 9 & $4-\mathrm{COCH}_{3}$ & $46.63( \pm 1.361)$ & $-3.22( \pm 1.203)$ & $-5.04( \pm 1.333)$ & 0.8907 & 0.505 & 13 & 10 \\
\hline 10 & $4-\mathrm{NO}_{2}$ & $40.29( \pm 0.500)$ & $-1.68( \pm 0.448)$ & $-3.15( \pm 0.461)$ & 0.9407 & 0.143 & 31 & 11 \\
\hline
\end{tabular}

a Correlation coefficient.

b Standard error of the estimate.

c Fisher's test.

${ }^{d}$ Number of solvents included in correlation.

Table 3

Percentage contribution of the two solvatochromic parameters of Eq. (1).

\begin{tabular}{llll}
\hline No. & Substituent & $\mathrm{P}_{\pi^{*}}(\%)$ & $\mathrm{P} \alpha(\%)$ \\
\hline 1 & $4-\mathrm{OH}$ & 43 & 57 \\
2 & $4-\mathrm{OCH}_{3}$ & 37 & 63 \\
3 & $4-\mathrm{CH}_{3}$ & 53 & 47 \\
4 & $\mathrm{H}$ & 23 & 77 \\
5 & $4-\mathrm{Cl}$ & 58 & 42 \\
6 & $4-\mathrm{Br}$ & 49 & 51 \\
7 & $4-\mathrm{I}$ & 25 & 75 \\
8 & $4-\mathrm{COOH}$ & 51 & 49 \\
9 & $4-\mathrm{COCH}_{3}$ & 39 & 61 \\
10 & $4-\mathrm{NO}_{2}$ & 35 & 65 \\
\hline
\end{tabular}

$s=\rho \cdot \sigma+h$

where $s$ is the substituent-dependent value: absorption wavenumbers $\left(\nu_{\max }\right), \rho$ is the proportionality constant expressing the sensitivity of $\nu_{\max }$ to the substituent effects, $\sigma$ is the corresponding substituent constant (measuring the electronic effect of the substituents), and $h$ is the intercept (i.e., describes $\nu_{\max }$ of the unsubstituted member of the series, $\sigma=0$ ).

From Table 1 it can be observed that the UV absorption maxima of the amides with both electron-donating and electron-accepting substituents are shifted to higher wavelengths in all pure solvents and their binary mixtures, as compared to the unsubstituted amide 4.

The plots $\nu_{\max } v s$. the $\sigma_{\mathrm{p}}$ [17] and $\sigma_{\mathrm{p}}^{+}$[18] substituent constants show deviations from the Hammett equation, therefore the effect of the electron-donating and electron-accepting substituents are taken into consideration separately. Different slopes for electrondonating substituents $\left(-\mathrm{OH},-\mathrm{OCH}_{3},-\mathrm{CH}_{3}\right)$, and electronaccepting substituents $\left(-\mathrm{Cl},-\mathrm{Br},-\mathrm{I},-\mathrm{COOH},-\mathrm{COCH}_{3},-\mathrm{NO}_{2}\right)$ are acquired in all solvents and binary mixtures. A better correlation of $\nu_{\max }$ is obtained with the electrophilic $\sigma_{\mathrm{p}}^{+}$substituent constants than with the $\sigma_{\mathrm{p}}$ constants, indicating an extensive electron delocalization in the aryl amide part of the molecule. Fig. 2 shows the dependence of $\nu_{\max }$ on the $\sigma_{\mathrm{p}}^{+}$constants for all succinimides (excluding 7) in pure solvents and binary mixtures.

For electron-accepting substituents, linear correlations of the absorption wavenumbers, $v_{\max }$, and the substituent constants, $\sigma_{\mathrm{p}}^{+}$, with high values of the proportionality constant, $\rho$, are obtained indicating, a significant influence of the electronic effect of these groups on the $\pi$-electron density transmission according to the mesomeric structures presented in Fig. 1. Moreover, significantly lower values of the proportionality constant and their positive sign for electron-donating substituents indicate larger solvent effects which diminish the substituent effect on the electronic transition due to their interaction with the amide group of the succinimide ring.

${ }^{13} \mathrm{C}$ NMR chemical shifts of the signals for the two carbonyl $\mathrm{C}$ atoms in succinimide moiety (Scheme 1) for the ten of 1-aryl-3methylsuccinimides are given in Table 5 as the substituent chemical shifts (SCS) compared to the parent compound 4 . Table 5 shows that electron-donating substituents exhibit downfield shifts, compounding to a decrease in electron density at both atoms, whereas electron-accepting substituents induce an opposite effect, related to an increase of electron density at both atoms (upfield shift).

For a quantitative assessment of the substituent effects on the ${ }^{13} \mathrm{C}$ NMR data of 1-10, analogously to Eq. (2) the LFER Eq. (3) has been applied. A better correlation of ${ }^{13} \mathrm{C}$ SCSs for C2 and C5 is achieved with the $\sigma_{\mathrm{p}}$ substituent constants than with the $\sigma_{\mathrm{p}}^{+}$constants. The electronic effects of the substituents have no influence on the SCS of C3 and C4 of the succinimide ring. From the $\rho$ values given in Table 6 it can be noticed that there is no significant difference in the influence of electronic effects of substituents on the C2 and C5 chemical shifts indicating a moderate impact of the substituents on the phenyl nucleus on the electron density of the investigated atoms. These results are in complete accordance with the molecular structure of 1-aryl-3-methylpyrrolidine-2,5-dione as well as with the mechanism of transmission of the substituent electronic effects throughout the molecule shown in Fig. 1.

\subsection{Computational studies}

\subsubsection{Theoretical calculation of optimal geometries and spectral data}

2.2.1.1. Conformational stability of the investigated succinimides. A conformational analysis was carried out for the succinimides 1-10 in order to locate all stable conformers. Their geometries are very rigid, so the only conformational changes are possible in the position of the methyl and phenyl groups. As the rotation of the methyl group shows a negligible change in the energy of the system, only the positions of the phenyl group are investigated. For a better insight in changes of energy as a consequence of the phenyl rotation, a potential energy scan (PES) was done. During the calculation, all geometrical parameters were simultaneously relaxed while the torsion angle $\theta$ (rotation around $\mathrm{N} 1-\mathrm{C}(\mathrm{Ph})$ bond, see Scheme 1) was varied in steps of $5^{\circ}$ from 0 to $360^{\circ}$ (Fig S1, Supplementary material). Results show that only two conformers for the molecule with symmetric substituents and four conformers for asymmetric substituents are possible.

The full geometry optimizations of these conformers were performed by B3LYP [19], CAM-B3LYP [20], and M06-2X [21] 
Table 4

The results of the correlation between $v_{\max } \times 10^{-3} / \mathrm{cm}^{-1}$ and $\sigma_{\mathrm{p}}^{+}$for the 1-aryl-3-methylsuccinimides.

\begin{tabular}{|c|c|c|c|c|c|}
\hline Solvent & $v_{\max } v s . \sigma_{\mathrm{p}+}$ & $\mathrm{R}^{\mathrm{a}}$ & $s^{b}$ & $\mathrm{~F}^{\mathrm{c}}$ & Compound $^{\mathrm{d}}$ \\
\hline \multirow[t]{2}{*}{ Methanol } & $(D): v_{\max }=46.795+3.700 \sigma_{\mathrm{p}+}$ & 0.982 & 0.368 & 55 & \\
\hline & $(\mathrm{A}): v_{\max }=46.288-12.631 \sigma_{\mathrm{p}+}$ & 0.986 & 0.716 & 136 & 7 \\
\hline \multirow[t]{2}{*}{ Methanol/ $\mathrm{H}_{2} \mathrm{O}(80: 20)$} & $(D): v_{\max }=46.433+4.567 \sigma_{\mathrm{p}+}$ & 0.976 & 0.526 & 41 & \\
\hline & $(\mathrm{A}): v_{\max }=46.052-13.751 \sigma_{\mathrm{p}+}$ & 0.992 & 0.580 & 246 & 7 \\
\hline \multirow[t]{2}{*}{ Methanol/ $\mathrm{H}_{2} \mathrm{O}(60: 40)$} & $(D): v_{\max }=46.313+4.867 \sigma_{\mathrm{p}+}$ & 0.975 & 0.575 & 39 & \\
\hline & $(\mathrm{A}): v_{\max }=46.095-13.039 \sigma_{\mathrm{p}+}$ & 0.985 & 0.743 & 135 & 7 \\
\hline \multirow[t]{2}{*}{ Methanol/ $\mathrm{H}_{2} \mathrm{O}(40: 60)$} & $(D): v_{\max }=46.226+4.234 \sigma_{\mathrm{p}+}$ & 0.946 & 0.753 & 17 & \\
\hline & $(\mathrm{A}): v_{\max }=45.935-12.790 \sigma_{\mathrm{p}+}$ & 0.990 & 0.612 & 192 & 7 \\
\hline \multirow[t]{2}{*}{ Ethanol } & (D): $v_{\max }=46.281+2.974 \sigma_{\mathrm{p}+}$ & 0.959 & 0.456 & 23 & \\
\hline & $(\mathrm{A}): v_{\max }=45.988-11.904 \sigma_{\mathrm{p}+}$ & 0.978 & 0.845 & 87 & 7 \\
\hline \multirow[t]{2}{*}{ Ethanol $/ \mathrm{H}_{2} \mathrm{O}(80: 20)$} & (D): $v_{\max }=46.257+3.092 \sigma_{\mathrm{p}+}$ & 0.967 & 0.422 & 29 & \\
\hline & $(\mathrm{A}): v_{\max }=46.031-11.710 \sigma_{\mathrm{p}+}$ & 0.979 & 0.805 & 93 & 7 \\
\hline \multirow{2}{*}{ Ethanol $/ \mathrm{H}_{2} \mathrm{O}(60: 40)$} & (D): $v_{\max }=46.019+2.267 \sigma_{\mathrm{p}+}$ & 0.972 & 0.284 & 35 & \\
\hline & $(\mathrm{A}): v_{\max }=46.461-11.720 \sigma_{\mathrm{p}+}$ & 0.969 & 0.988 & 62 & 7 \\
\hline \multirow[t]{2}{*}{ Ethanol/ $\mathrm{H}_{2} \mathrm{O}(40: 60)$} & (D): $v_{\max }=46.181+2.727 \sigma_{\mathrm{p}+}$ & 0.985 & 0.246 & 66 & \\
\hline & $(\mathrm{A}): v_{\max }=46.631-11.821 \sigma_{\mathrm{p}+}$ & 0.954 & 1.224 & 41 & 7 \\
\hline \multirow[t]{2}{*}{ 2-Propanol } & (D): $v_{\max }=45.468+2.819 \sigma_{\mathrm{p}+}$ & 0.933 & 0.566 & 13 & \\
\hline & $(\mathrm{A}): v_{\max }=45.776-10.808 \sigma_{\mathrm{p}+}$ & 0.964 & 0.985 & 53 & 7 \\
\hline \multirow[t]{2}{*}{ 2-Propanol/ $\mathrm{H}_{2} \mathrm{O}(80: 20)$} & $(D): v_{\max }=46.062+2.246 \sigma_{\mathrm{p}+}$ & 0.999 & 0.021 & 5971 & \\
\hline & $(\mathrm{A}): v_{\max }=45.925-11.634 \sigma_{\mathrm{p}+}$ & 0.991 & 0.516 & 223 & 7 \\
\hline \multirow[t]{2}{*}{ 2-Propanol/ $\mathrm{H}_{2} \mathrm{O}(60: 40)$} & (D): $v_{\max }=46.045+2.609 \sigma_{\mathrm{p}+}$ & 0.977 & 0.295 & 42 & \\
\hline & $(\mathrm{A}): v_{\max }=46.095-11.768 \sigma_{\mathrm{p}+}$ & 0.997 & 0.288 & 732 & 7 \\
\hline \multirow[t]{2}{*}{ 2-Propanol/ $\mathrm{H}_{2} \mathrm{O}(40: 60)$} & $(D): v_{\max }=46.161+2.572 \sigma_{\mathrm{p}+}$ & 0.985 & 0.237 & 64 & \\
\hline & $(\mathrm{A}): v_{\max }=46.252-12.016 \sigma_{\mathrm{p}+}$ & 0.992 & 0.504 & 250 & 7 \\
\hline \multirow[t]{2}{*}{ 2-Propanol/Ethanol(80:20) } & $(D): v_{\max }=46.258+3.745 \sigma_{\mathrm{p}+}$ & 0.975 & 0.447 & 38 & \\
\hline & $(\mathrm{A}): v_{\max }=45.939-11.760 \sigma_{\mathrm{p}+}$ & 0.993 & 0.460 & 287 & 7 \\
\hline \multirow[t]{2}{*}{ 2-Propanol/Ethanol(60:40) } & (D): $v_{\max }=46.037+2.523 \sigma_{\mathrm{p}+}$ & 0.964 & 0.363 & 26 & \\
\hline & $(\mathrm{A}): v_{\max }=45.898-11.456 \sigma_{\mathrm{p}+}$ & 0.995 & 0.377 & 405 & 7 \\
\hline \multirow[t]{2}{*}{ 2-Propanol/Ethanol(40:60) } & $(D): v_{\max }=45.936+2.629 \sigma_{\mathrm{p}+}$ & 0.978 & 0.295 & 43 & \\
\hline & $(\mathrm{A}): v_{\max }=45.874-12.706 \sigma_{\mathrm{p}+}$ & 0.995 & 0.402 & 438 & 7 \\
\hline \multirow[t]{2}{*}{ 2-Propanol/Methanol (80:20) } & (D): $v_{\max }=45.773+2.630 \sigma_{\mathrm{p}+}$ & 0.987 & 0.222 & 76 & \\
\hline & $(\mathrm{A}): v_{\max }=45.656-11.818 \sigma_{\mathrm{p}+}$ & 0.991 & 0.540 & 210 & 7 \\
\hline \multirow[t]{2}{*}{ 2-Propanol/Methanol (60:40) } & $(D): v_{\max }=46.032+2.796 \sigma_{\mathrm{p}+}$ & 0.988 & 0.223 & 85 & \\
\hline & $(\mathrm{A}): v_{\max }=45.841-11.827 \sigma_{\mathrm{p}+}$ & 0.993 & 0.467 & 281 & 7 \\
\hline \multirow[t]{2}{*}{ 2-Propanol/Methanol (40:60) } & (D): $v_{\max }=45.974+2.607 \sigma_{\mathrm{p}+}$ & 0.981 & 0.271 & 50 & \\
\hline & $(\mathrm{A}): v_{\max }=45.942-12.078 \sigma_{\mathrm{p}+}$ & 0.995 & 0.417 & 368 & 7 \\
\hline
\end{tabular}

a Correlation coefficient.

b Standard error of the estimate.

c Fisher's test.

d Succinimide derivative excluded from correlation (number as given in Scheme 1).

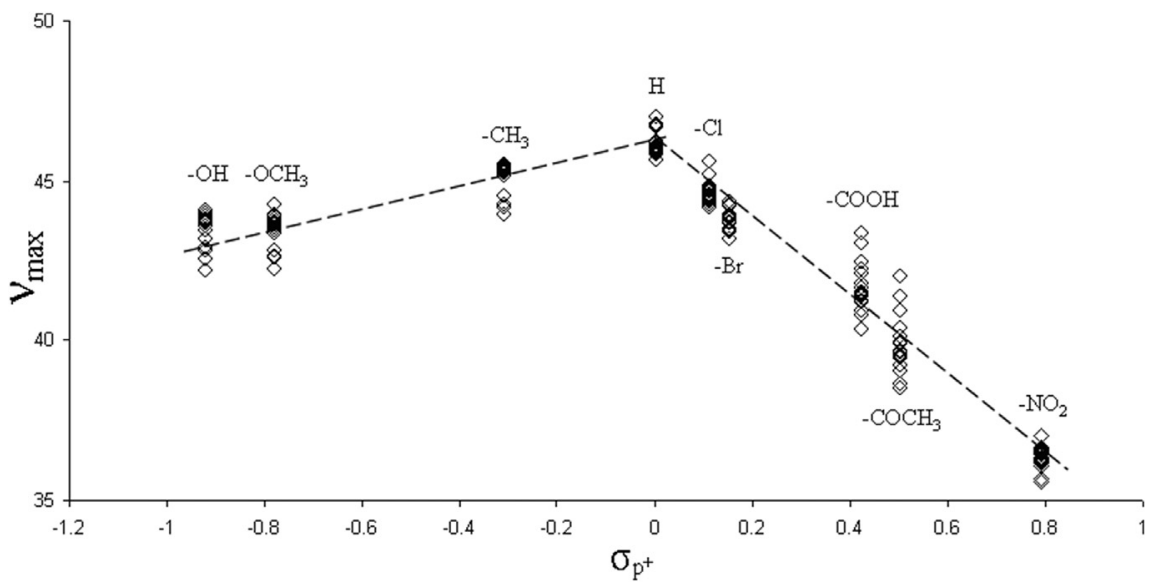

Fig. 2. Relationship between $\nu_{\max }$ and $\sigma_{\mathrm{p}}^{+}$for the 1-aryl-3-methylsuccinimides 1-6 and 8-10.

methods with the $6-311 \mathrm{G}(\mathrm{d}, \mathrm{p})$ basis set in the vacuum and solvents (ethanol and DMSO). The results provided from these calculations are used for different analyses in this work. The geometries of the most stable conformers for compound $\mathbf{4}$ according to B3LYP method are shown in Fig. 3.

The conformers have similar energies which differ from the energy of the most stable isomer by less than $0.20 \mathrm{kcal} / \mathrm{mol}$, depending on substituent and the method of calculation. According to a Boltzmann analysis, they are simultaneously present in the mixture. The properties of interest are simulated based on the static results (the most stable conformer is used) and some of them as the dynamic results (Boltzmann averaging procedure is applied), too.

Analyzing the results of calculations from default integration grid (FineGrid), the disagreement between the prediction of the 
Table 5

${ }^{13} \mathrm{C}$ NMR substituent chemical shifts ( $\left.\delta / \mathrm{ppm}\right)$.

\begin{tabular}{llll}
\hline No. & Substituents & \multicolumn{2}{l}{ SCS in $\delta / \mathrm{ppm}$} \\
\cline { 3 - 4 } & & $\mathrm{C} 2$ & $\mathrm{C} 5$ \\
\hline 1 & $4-\mathrm{OH}$ & 0.3 & 0.3 \\
2 & $4-\mathrm{OCH}_{3}$ & 0.2 & 0.2 \\
3 & $4-\mathrm{CH}_{3}$ & 0.1 & 0.1 \\
4 & $\mathrm{H}$ & $(180.2)$ & $(176.1)$ \\
5 & $4-\mathrm{Cl}$ & -0.3 & -0.2 \\
6 & $4-\mathrm{Br}$ & -0.3 & -0.2 \\
7 & $4-\mathrm{I}$ & -0.3 & -0.2 \\
8 & $4-\mathrm{COOH}$ & -0.4 & -0.3 \\
9 & $4-\mathrm{COCH}_{3}$ & -0.4 & -0.4 \\
10 & $4-\mathrm{NO}_{2}$ & -0.6 & -0.5 \\
\hline
\end{tabular}

Table 6

Results of the SCS data correlations according to Eq. (2).

\begin{tabular}{lllllll}
\hline Parameter & $\rho$ & $h$ & $\mathrm{R}^{\mathrm{a}}$ & $\mathrm{s}^{\mathrm{b}}$ & $\mathrm{F}^{\mathrm{c}}$ & $\mathrm{n}^{\mathrm{d}}$ \\
\hline$\delta_{\mathrm{C}(\mathrm{C} 2)}$ & $-0.803( \pm 0.048)$ & $/^{\mathrm{e}}$ & 0.9858 & 0.053 & 276 & 10 \\
$\delta_{\mathrm{C}(\mathrm{C} 5)}$ & $-0.708( \pm 0.032)$ & $/^{\mathrm{e}}$ & 0.9920 & 0.035 & 493 & 10 \\
\hline
\end{tabular}

a Correlation coefficient.

b Standard error of the estimate.

c Fisher's test.

d Number of compounds included in correlation.

e Negligible value with high standard error. calculations shows negligible effects on the ratio of conformers from B3LYP and CAM-B3LYP methods in vacuum. The impact of integration grid is notable for both methods in ethanol as solvent. The M06-2X method shows a significant influence of the used integration grid which change the ratio and detection of the most stable conformer to a large extent. After implementing UltraFineGrid, all three methods show agreements in the detection of conformer A (or A2) as the most stable in vacuum. All three methods predict conformer B (or B2) as the most stable in ethanol solution.

The torsion angle $\theta$ determines the deviation from planarity (Scheme 1). It can serve as a rough measure for the efficient transfer of substituent's resonance effect from phenyl to succinimide ring and its accurate determination is directly connected with the accurate prediction of all properties altered by substituent. The analyses of the optimized geometries show that the biggest difference between the applied methods occurs exactly in predicting of this torsion angle (see Table S2).

The applied methods predict a torsion angle $\theta$ from 37 to $45^{\circ}$ in vacuum, depending on the substituent. Methods with the $\mathrm{CPCM}$ model for simulation of solvent (ethanol and DMSO) predict a much larger value for this angle, i.e., from 45 to $72^{\circ}$. The B3LYP method predicts slightly higher values than the CAM-B3LYP and M06-2X methods in vacuum, while the difference becomes much higher when the simulation of the solvent is introduced (B3LYP - 47-72 ,

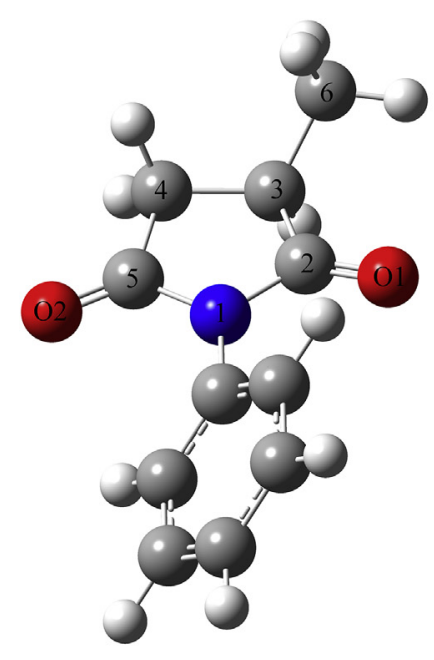

A

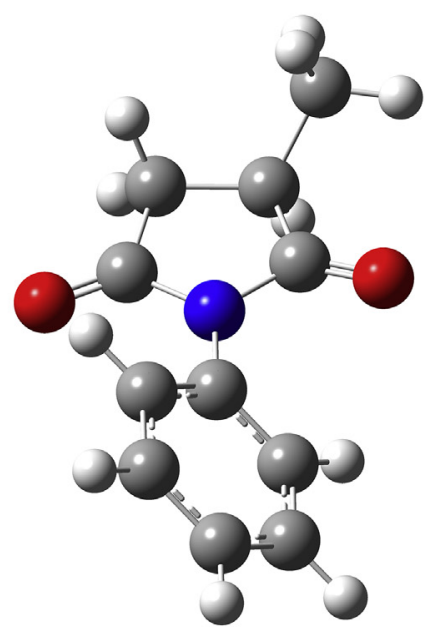

B

Fig. 3. The most stable conformers of compound $\mathbf{4}$ calculated by B3LYP level of theory.

most stable conformers, as well as, the ratio in the mixture were observed for different methods (see Table S1, Supplementary material). The B3LYP and CAM-B3LYP methods in vacuum predict conformer A (or A2) as the most stable conformer and in the same time B3LYP method predict conformer B (or B2) as the most stable conformer in ethanol solution for all investigated compounds. The CAM-B3LYP method for ethanol as a solvent, as well as the M06-2X method, do not show agreement in the prediction of the ratio and the most stable conformer of all investigated compounds.

As the influence of the integration grid can be potentially significant for the accurate prediction of geometry and energy of conformers, especially for the M06 suite of functionals [22], the additional reoptimization of geometries are done using the pruned 99,590 integration grid (UltraFineGrid).

Comparison of the results from FineGrid and UltraFineGrid

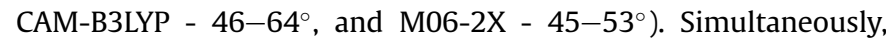
implementation of UltraFineGrid leads to additional changes in the torsion angle $\theta$ which becomes more reliable, especially for the M06-2X method.

2.2.1.2. Theoretical calculation of UV-Vis spectral data. It is well known that an accurately determined geometry is essential for a good prediction of physicochemical properties, especially if the investigated compounds can exist in different tautomeric or conformational states. The solvent can change the geometry and energy of conformers and on that way affect the ratio of conformers in a mixture. The electronic property and UV/Vis absorption spectrum of a mixture depend on all present particles as well as of their interactions. For the accurate determination of conformers, their ratio in the mixture and their interaction with the solvent, the 
selection of an appropriate computational system is of crucial importance [23-26].

In order to obtain the UV properties of the investigated succinimides, TD-DFT methods are performed using different types of functionals: B3LYP [19], CAM-B3LYP [20], and M06-2X [21] (hybrid GGA, hybrid with improved long-range properties and hybrid meta-GGA functional) with the $6-311 G(d, p)$ basis set have been tested. Jacquemin et al. have demonstrated that these functionals provide satisfying UV spectra compared to experiments for twenty conjugated molecules [24]. Also, they have evaluated other effects such as basis set, integration grid, temperature, and cavities in the Polarizable Continuum Model scheme.

The static method ensures good results for rigid organic compounds for application in analytical chemistry. On the other hand, when an organic compound exists in more than one conformer, then for the accurate prediction of UV-Vis spectra molecular dynamic (MD) methods [27,28] or simulations based on Boltzmann averaging should be used since static calculations are unsatisfactory [29]. In molecules in which flexibility is of importance, these calculations are often required. Therefore, the theoretical explanation of the experimental UV spectra should not include only electronic effects.

The impact of the integration grid can be potentially significant and has also been studied [22]. For a benchmark purpose we used the Euler-Maclaurin integration and pruned 75,302 grid, constituted of 75 radial and 302 angular points (FineGrid) and a tighter pruned 99,590 grid (UltraFineGrid).

The electronic absorption spectrum of 1-phenyl-3methylpyrrolidine-2,5-dione $\mathbf{4}$ in ethanol as solvent was recorded in the range of $200-400 \mathrm{~nm}$. The experimental spectrum is shown on Fig. 4 together with the calculated spectrum and the electronic transitions obtained with the B3LYP method.

As can be seen from Fig. 4 and Fig. S2, the electronic absorption spectrum of compound 4 shows only one low-intensity band at $216 \mathrm{~nm}$. Also, all TD-DFT calculations predict only one low-intense electronic absorption with an oscillator strength of $f<0.25$. The shape of the calculated spectrum is in good agreement with the experimental one. The electronic absorption corresponds to a transition from the ground to the higher excited states (fourth or fifth, depending on the model used for calculation). It can be described as a $\pi \rightarrow \pi^{*}$ transition which corresponds to a oneelectron excitation from the highest occupied molecular orbital (HOMO) to the lowest unoccupied molecular orbital (LUMO) or to the second lowest unoccupied molecular orbital (LUMO+1) orbital (see Fig. 4).

In accordance with the aforesaid, the correlations of experimental and calculated absorption UV maxima for compounds 1-10 are done. Values for the experimentally recorded and computationally determined position of the UV maxima for all (located) conformers of compounds $\mathbf{1 - 1 0}$ by TD methods are listed in Table S3.

From the results presented in Tables S4 and S5, it can be seen that the best correlation is provided between experimental and calculated UV maxima from a TD calculation with the B3LYP method in vacuum. A graphical representation of the relationship between them is shown in Fig. 5. The CAM-B3LYP and M06-2X methods in vacuum highly underestimate the values of the UV maxima but still produce good correlation results $R^{2}>0.9$.

Introduction of the solvent effect in the calculation produces a different impact on the calculated UV maxima. The B3LYP calculations produce values that mostly overestimate the experimental one with the lower correlation quality. The UV values provided from CAM-B3LYP method shows a very low impact on the correlation quality. However, the improvement of the slope and interception is evident. The M06-2X method shows the largest positive effect from introduction of the solvent to the correlation quality.

The influence of the integration grid on the quality of the obtained UV results is tested and shows small but positive impacts on the correlation results. Only the M06-2X method with the simulation of solvent shows the biggest benefit from an implementation of a tighter integration grid. These results are in agreement with results of other authors [22,23].

The used DFT methods show that conformers are simultaneously present in the mixture but also TD DFT methods predict

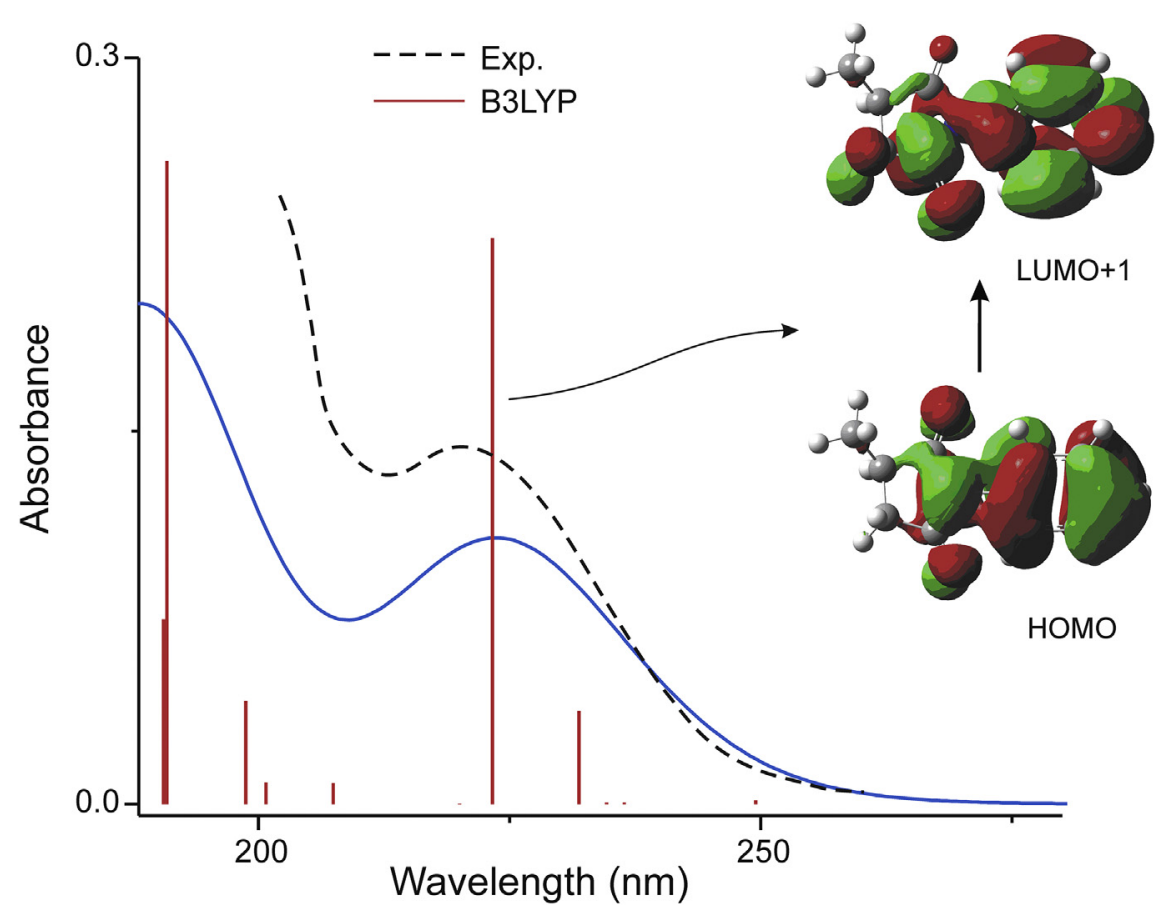

Fig. 4. Experimental UV spectrum of 1-phenyl-3-methylpyrrolidine-2,5-dione 4, measured in ethanol, and the calculated TD-B3LYP electronic absorption spectrum in vacuum. 


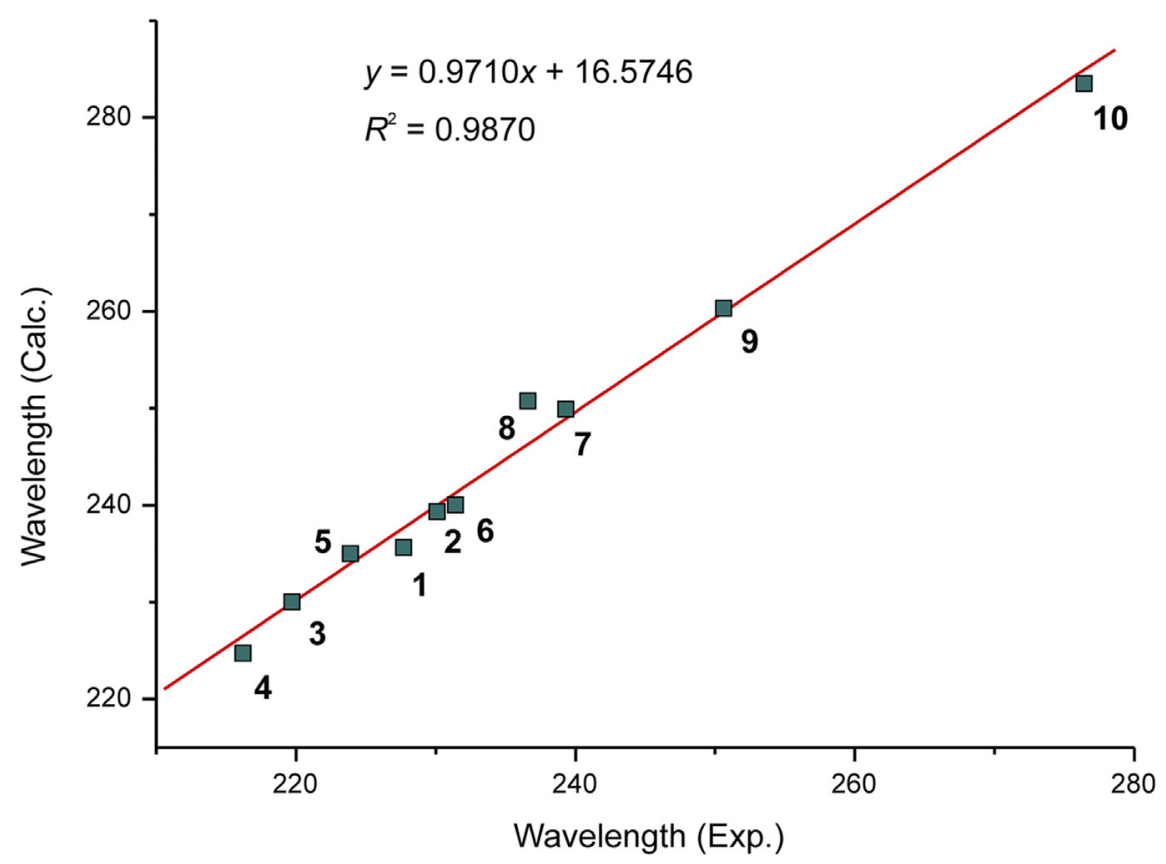

Fig. 5. Correlation between experimental and calculated UV maxima provided by the B3LYP method in a vacuum.

difference of less then $2 \mathrm{~nm}$ between conformers $\mathrm{A}$ and B. In accordance with that, simulated UV values based on the static or dynamic results produce a relatively small impact but it is directly connected with the introduction of the solvent effects. The dynamic UV values (produced with Boltzmann averaging procedure) simulated in vacuum show a notable improvement in comparison to static results. Contrary, the UV values simulated in ethanol as solvent, show better correlations when the static values (simulated from most stable conformer) are used.

\subsubsection{Electronic analysis}

The frontier molecular orbitals (FMO), the highest occupied molecular orbital (HOMO) and the lowest unoccupied molecular orbital (LUMO), define the UV-Vis spectra and the electric and optical properties. The FMO is useful in the estimation of the chemical reactivity of a molecule as well as that part of the molecule which interacts with other molecules, and in characterization of the kinetic stability of the molecule. A low-frontier orbital gap indicates a more polarizable molecule and a higher reactivity, but also a low kinetic stability [30]. Energies of HOMO and LUMO and the energy gap between them for $\mathbf{2}, \mathbf{4}, \mathbf{5}$, and $\mathbf{1 0}$ molecule calculated at the B3LYP method with $6-311 G(d, p)$ basis set are shown in Fig. S3.

The energies of the frontier MOs (HOMO and LUMO) and the energy gap between them indicate a significant influence of the nature of the substituent introduced in 4-position of the phenyl ring. The introduction of electron-donating or electronwithdrawing substituent leads to a decrease in the energy gap (a smaller decrease for electron-donating and a larger decrease for electron-withdrawing substituents).

2.2.2.1. The torsion angle $(\theta)$. For the quantitative assessment of the substituent effects on the torsion angle $\theta$ of the most stable conformers (Table S6) a conventional LFER model (Eq. (2)) have been used. A better correlation of $\cos ^{2} \theta$ is obtained with the $\sigma_{\mathrm{p}}^{+}$substituent constants (Eq. (3)) compared to the $\sigma_{\mathrm{p}}$ constants. The results obtained indicate an intramolecular charge transfer (ICT) from substituent to amid moiety of the succinimide ring. Moreover, the positive sign of the proportional constant is in complete accordance with the mechanism of transmission of the substituent electronic effects throughout the molecule given in Fig. 1, where electronacceptor substituents induce a higher bathochromic band shift compared to the electron-donating substituents. It can be observed that the degree of deviation from the planarity of molecule, between succinimid and phenyl ring, is in relationship with the electronic character of the substituent.

$\cos ^{2} \theta=0.321+0.183 \sigma_{\mathrm{p}}^{+}$

$(\mathrm{R}=0.982 \mathrm{~s}=0.020 ; \mathrm{F}=215 ; \mathrm{n}=10)$

2.2.2.2. NBO and APT charge data (correlations with partial atomic charges). Calculated partial atomic charges are often utilized for an interpretation of the changes of dipole moment, molecular polarizability, and molecular electronic structure. Also, the chemical activity of the molecule can be interpreted on the basis of atomic charges transfer [30].

The values of partial atomic charges from the atomic polar tenzors (APT) [31], natural population analysis (NBO) procedures [32], and charges fit to the electrostatic potential according to Merz-Singh-Kollman [33], CHelp [34], and CHelpG [35] schemes using the B3LYP, CAM-B3LYP, and M06-2X methods are produced and correlated with different experimental properties. An LFER analysis is applied to NBO, APT, and Electrostatic Potential (EP) data of investigated atoms $(\mathrm{C} 2, \mathrm{C} 5, \mathrm{O} 1, \mathrm{O} 2, \mathrm{~N} 1)$, using Eq. (2) and the results obtained for APT data are given in Table 7. Results derived from Eq. (2) for NBO and EP data are statistically excellent and in the agreement with correlations of APT charges (Table S7).

The better correlation with $\sigma_{p}$ than with $\sigma_{p}^{+}$for all investigated atoms (in DMSO) is an excellent indicator that electron transmission through the molecule is in good accordance with the mesomeric structures proposed in Fig. 1. From Table 7, it can be observed that electron-donating groups induce an increase in electron density on the $\mathrm{O} 1=\mathrm{C} 2-\mathrm{N} 1-\mathrm{C} 5=\mathrm{O} 2$ part of the 
Table 7

Results of the APT data in DMSO as solvent, derived from B3LYP/6-311G(d,p) correlated with Eq. (2).

\begin{tabular}{|c|c|c|c|c|c|c|c|c|}
\hline Parameter & Constant & Solvent & $\rho$ & $h$ & $\mathrm{R}^{\mathrm{a}}$ & $\mathrm{s}^{\mathrm{b}}$ & $\mathrm{F}^{\mathrm{c}}$ & $\mathrm{n}^{\mathrm{d}}$ \\
\hline \multicolumn{9}{|l|}{$\mathrm{Q}_{(\mathrm{APT})}$} \\
\hline $\mathrm{C} 2$ & $\sigma_{p}$ & DMSO & $0.036( \pm 0.002)$ & $1.428( \pm 0.000)$ & 0.9858 & 0.002 & 275 & 10 \\
\hline C5 & $\sigma_{p}$ & DMSO & $0.033( \pm 0.003)$ & $1.467( \pm 0.001)$ & 0.9701 & 0.003 & 127 & 10 \\
\hline 01 & $\sigma_{p}$ & DMSO & $0.020( \pm 0.001)$ & $-1.002( \pm 0.000)$ & 0.9879 & 0.001 & 324 & 10 \\
\hline $\mathrm{O} 2$ & $\sigma_{p}$ & DMSO & $0.020( \pm 0.001)$ & $-1.015( \pm 0.000)$ & 0.9860 & 0.001 & 281 & 10 \\
\hline N1 & $\sigma_{p}$ & DMSO & $-0.221( \pm 0.010)$ & $-1.268( \pm 0.004)$ & 0.991 & 0.011 & 451 & 10 \\
\hline
\end{tabular}

succinimide ring, while electron-accepting ones cause an opposite effect. Moreover, substituents in 4-position of the phenyl ring have no influence on the changes of electron density on the rest part of the succinimide ring $(\mathrm{C} 3, \mathrm{C} 4, \mathrm{C} 6)$.

2.2.2.3. Molecular electrostatic potential. The molecular electrostatic potential (MEP) is often used for prediction of the reactivity of the chemical species in nucleophilic and electrophilic reactions, since MEP is associated with the electron density. For this purpose, the MEP at the B3LYP/6-311G(d,p) optimized geometry for succinimides 1-10 was calculated. Red and yellow colored regions (negative) of the MEP represent sites of electrophilic reactivity, whereas red regions (positive) refers to nucleophilic sites, as shown in Fig. 6 (MEP).

As it can be seen from Fig. 6, the molecule of the $\mathbf{4}$ (in vacuum) has two possible sites for electrophilic and one site for nucleophilic attack. Negative regions of $\mathbf{4}$ are located around the carbonyl oxygen atoms and a moderate positive region is localized on the $\mathrm{H}$ atoms of the methylene group from the succinimide ring.

\subsection{Computational vs spectroscopic data}

The UV-Vis absorption spectra are highly dependent on the energy of frontier molecular orbitals among which electronic transition occurs. The spreading and energy of FMO's are dependent on the torsion angle $\theta$, which reflect deviation from planarity of the planes in which succinimide and phenyl rings lay. The relations of $\cos ^{2} \theta$ derived from B3LYP method for the most stable conformers of the investigated compounds vs. UV absorption

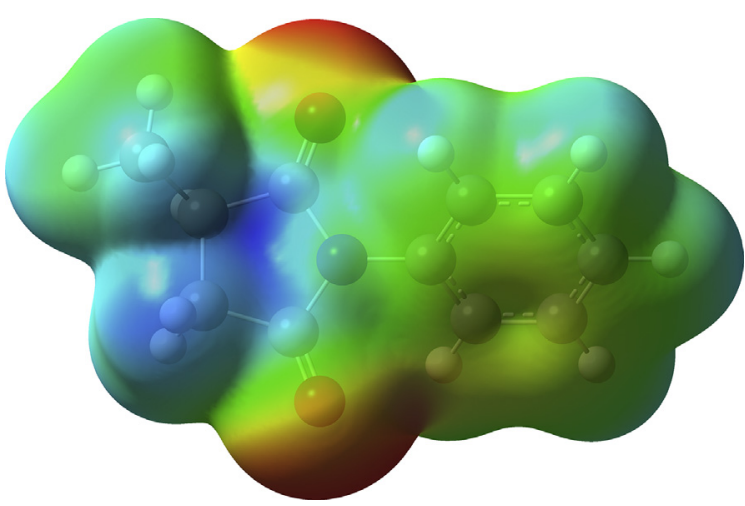

Fig. 6. Electrostatic potentials map of 1-phenyl-3-methylpyrrolidine-2,5-dione 4 in vacuum from B3LYP/6-311G(d,p) calculation plotted on isosurfaces of 0.002 a.u. electron density); color coding: red (very negative), orange (negative), yellow (slightly negative), green (neutral), turquoise (slightly positive), light blue (positive), dark blue (very positive). (For interpretation of the references to colour in this figure legend, the reader is referred to the web version of this article.) maxima data have been calculated (Fig. 7). An excellent linear correlation is obtained with ethanol as solvent. The result is in accordance with previously described results obtained from applied Hammett equation on the UV absorption wavenumbers (Fig. 2).

As NMR shifts depend on shielding effects, which are directly influenced by substituent electronic effects and electron distribution, NBO, APT, and EP data obtained with B3LYP method for investigated compounds in DMSO are correlated with experimental SCS data (Table 8).

Excellent relations between experimental and theoretical data directly indicate high validity and precision of proposed models.

\section{Experimental}

Commercially available materials were obtained from Aldrich and Fluka, and were used without further purification. All investigated 1-aryl-3-methylpyrrolidine-2,5-diones were synthesized from 2-methylsuccinic acid and the corresponding anilines under solvent-free conditions (Scheme 2) as described previously [3]. The products were purified by crystallization from an ethanol/water mixture. The FT-IR spectra were determined using a Bomem Fourier Transform-Infrared (FT-IR) spectrophotometer, MB-Series 100 in the form of the $\mathrm{KBr}$ discs. The ${ }^{1} \mathrm{H}$ and ${ }^{13} \mathrm{C}$ NMR spectral measurements were performed on a Varian Gemini 2000 (200 MHz). The spectra were recorded at room temperature in deuterated dimethyl sulfoxide (DMSO- $d_{6}$ ). The chemical shifts are expressed in ppm values referenced to TMS. The ultraviolet (UV) absorption spectra were recorded on a Schimadzu 1700 spectrophotometer in the region 200-400 $\mathrm{nm}$. The UV absorption spectra were taken in spectroscopic quality solvents (Fluka) at a concentration of $5 \cdot 10^{-5} \mathrm{~mol} \mathrm{dm}^{-3}$ and showed no dependence on the concentration. All melting points were uncorrected and are in degree Celsius.

The molecular structure of compounds 1-10 was confirmed by UV, FT-IR, ${ }^{1} \mathrm{H}$ NMR, and ${ }^{13} \mathrm{C}$ NMR spectra. Characterization data are given below.

1-(4-Hydroxyphenyl)-3-methylpyrrolidine-2,5-dione $\left.\mathrm{C}_{11} \mathrm{H}_{11} \mathrm{NO}_{3}\right)$. Black solid; yield: $64 \%$; m.p.: $228-229^{\circ} \mathrm{C}\left(227-228^{\circ} \mathrm{C}\right)$ [36]; FT-IR (KBr): $v / \mathrm{cm}^{-1}=1771(\mathrm{C}=\mathrm{O}), 1695(\mathrm{C}=\mathrm{O}) ;{ }^{1} \mathrm{H}$ NMR (200 MHz, DMSO): $\delta / \mathrm{ppm}=9.81(\mathrm{~s}, 1 \mathrm{H},-\mathrm{OH}), 7.00(\mathrm{~d}, J=8.0 \mathrm{~Hz}$, $2 \mathrm{H}, \mathrm{N}-\mathrm{Ph}), 6.84(\mathrm{~d}, J=8.0 \mathrm{~Hz}, 2 \mathrm{H}, \mathrm{N}-\mathrm{Ph}), 3.10-2.89(\mathrm{~m}, 2 \mathrm{H}$, $-\mathrm{CH}_{2}-$ ), $2.51-2.39(\mathrm{~m}, 1 \mathrm{H},-\mathrm{CH}) 1.27\left(\mathrm{~d}, J=8.0 \mathrm{~Hz}, 3 \mathrm{H},-\mathrm{CH}_{3}\right) ;{ }^{13} \mathrm{C}$ NMR (50 MHz, DMSO): $\delta / \mathrm{ppm}=180.5$ (C2), 176.4 (C5), 159.2, 128.3, 125.6, 114.3 (Ph), 36.5 (C3), 34.7 (C4), 16.0 (C6).

1-(4-Methoxyphenyl)-3-methylpyrrolidine-2,5-dione $\left.\mathrm{C}_{12} \mathrm{H}_{13} \mathrm{NO}_{3}\right)$. Colorless solid; yield: $38 \%$; m.p.: $92-93{ }^{\circ} \mathrm{C}\left(91-93{ }^{\circ} \mathrm{C}\right)$ [37]; FT-IR (KBr): $v / \mathrm{cm}^{-1}=1773(\mathrm{C}=\mathrm{O}), 1704(\mathrm{C}=\mathrm{O})$; ${ }^{1} \mathrm{H}$ NMR (200 MHz, DMSO): $\delta / \mathrm{ppm}=7.19(\mathrm{~d}, J=8.0 \mathrm{~Hz}, 2 \mathrm{H}, \mathrm{N}-\mathrm{Ph}), 7.02(\mathrm{~d}$, $J=8.0 \mathrm{~Hz}, 2 \mathrm{H}, \mathrm{N}-\mathrm{Ph}), 3.78\left(\mathrm{~s}, 3 \mathrm{H},-\mathrm{OCH}_{3}\right), 3.02-2.90(\mathrm{~m}, 2 \mathrm{H}$, $\left.-\mathrm{CH}-+-\mathrm{CH}_{2}-\right), 2.53-2.38\left(\mathrm{~m}, 1 \mathrm{H},-\mathrm{CH}_{2}-\right), 1.28(\mathrm{~d}, J=8.0 \mathrm{~Hz}, 3 \mathrm{H}$, 


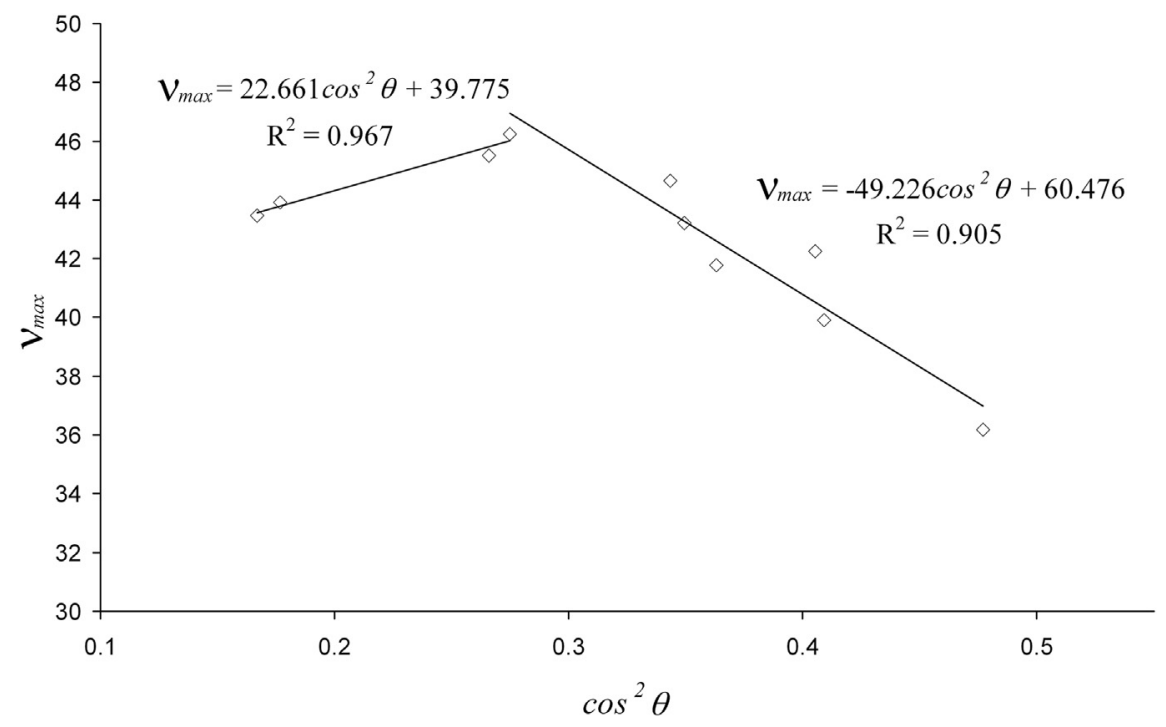

Fig. 7. $v_{\max } v s . \cos ^{2} \theta$ data for investigated 1-aryl-3-methylpyrrolidine-2,5-diones.

Table 8

APT, NBO, EP vs. SCS data for the 1-aryl-3-methylpyrrolidine-2,5-diones 1-10.

\begin{tabular}{llll}
\hline & Relation & $\mathrm{R}^{\mathrm{a}}$ & $\mathrm{n}^{\mathrm{b}}$ \\
\hline $\mathrm{C} 2_{\mathrm{Q}(\mathrm{APT})}$ & $A P T=-0.043 \cdot \mathrm{SCS}+1.426$ & 0.9621 & 10 \\
$\mathrm{C} 5$ & 0.9484 & 10 \\
$\mathrm{C} 2_{\mathrm{Q}(\mathrm{APT})}$ & $A P T=-0.046 \cdot \mathrm{SCS}+1.467$ & 0.9017 & 10 \\
$\mathrm{C} 5$ & $N B O=-0.003 \cdot \mathrm{S} C S+0.765$ & 0.9398 & 10 \\
$\mathrm{C} 2_{\mathrm{Q}(\mathrm{NBO})}$ & $N B O=-0.003 \cdot S C S+0.764$ & 0.9635 & 10 \\
$\mathrm{C} 5$ & $E P=-0.030 \cdot S C S-14.655$ & 0.9489 & 10 \\
\hline
\end{tabular}

a Correlation coefficient.

b Number of compounds included in correlation.
$\left.-\mathrm{CH}_{3}\right) ;{ }^{13} \mathrm{C}$ NMR (50 MHz, DMSO): $\delta / \mathrm{ppm}=180.2(\mathrm{C} 2), 176.1(\mathrm{C} 5)$, 133.0, 129.0, 128.4, 127.4 (Ph), 36.4 (C3), 34.7 (C4), 16.0 (C6).

1-(4-Chlorophenyl)-3-methylpyrrolidine-2,5-dione

(5,

$\left.\mathrm{C}_{11} \mathrm{H}_{10} \mathrm{ClNO}_{2}\right)$. Colorless solid; yield: 53\%; m.p.: $109-111{ }^{\circ} \mathrm{C}$ $\left(110-111{ }^{\circ} \mathrm{C}\right)$ [39]; FT-IR (KBr): $v / \mathrm{cm}^{-1}=1774(\mathrm{C}=\mathrm{O}), 1704(\mathrm{C}=\mathrm{O})$; ${ }^{1} \mathrm{H}$ NMR (200 MHz, DMSO): $\delta / \mathrm{ppm}=7.56(\mathrm{~d}, J=8.0 \mathrm{~Hz}, 2 \mathrm{H}, \mathrm{N}-\mathrm{Ph})$, $7.33(\mathrm{~d}, J=8.0 \mathrm{~Hz}, 2 \mathrm{H}, \mathrm{N}-\mathrm{Ph}), 3.10-2.92\left(\mathrm{~m}, 2 \mathrm{H},-\mathrm{CH}-+-\mathrm{CH}_{2}-\right)$, $2.57-2.40\left(\mathrm{~m}, 1 \mathrm{H},-\mathrm{CH}_{2}-\right), 1.29\left(\mathrm{~d}, J=8.0 \mathrm{~Hz}, 3 \mathrm{H},-\mathrm{CH}_{3}\right) ;{ }^{13} \mathrm{C} \mathrm{NMR}$ (50 MHz, DMSO): $\delta / \mathrm{ppm}=179.9$ (C2), 175.9 (C5), 132.8, 131.8, 129.1 (Ph), 36.4 (C3), 34.7 (C4), 15.8 (C6).<smiles>CC(CC(=O)O)C(=O)O</smiles><smiles>[X]c1ccc(N)cc1COCCO</smiles><smiles>[X]c1ccc(N2C(=O)CC(C)C2=O)cc1</smiles>

Scheme 2. Synthetic pathway for the 1-aryl-3-methylpyrrolidine-2,5-diones 1-10.

$\left.-\mathrm{CH}_{3}\right) ;{ }^{13} \mathrm{C}$ NMR (50 MHz, DMSO): $\delta / \mathrm{ppm}=180.4(\mathrm{C} 2), 176.3(\mathrm{C} 5)$, $159.1,128.6,125.5,114.2(\mathrm{Ph}), 55.5\left(\mathrm{C} 8,-\mathrm{OCH}_{3}\right), 36.4(\mathrm{C} 3), 34.6(\mathrm{C} 4)$, $16.0(\mathrm{C} 6)$.

1-(4-Methylphenyl)-3-methylpyrrolidine-2,5-dione

(3, $\left.\mathrm{C}_{12} \mathrm{H}_{13} \mathrm{NO}_{2}\right)$. Colorless solid; yield: 47\%; m.p.: 106-108 ${ }^{\circ} \mathrm{C}$ $\left(107-108^{\circ} \mathrm{C}\right)[38]\left(107^{\circ} \mathrm{C}\right)$ [36]; FT-IR (KBr): $v / \mathrm{cm}^{-1}=1776(\mathrm{C}=0)$, $1708(\mathrm{C}=\mathrm{O}) ;{ }^{1} \mathrm{H}$ NMR $(200 \mathrm{MHz}, \mathrm{DMSO}): \delta / \mathrm{ppm}=7.29(\mathrm{~d}$, $J=8.0 \mathrm{~Hz}, 2 \mathrm{H}, \mathrm{N}-\mathrm{Ph}), 7.15(\mathrm{~d}, J=8.0 \mathrm{~Hz}, 2 \mathrm{H}, \mathrm{N}-\mathrm{Ph}), 3.07-2.91(\mathrm{~m}$, $\left.2 \mathrm{H},-\mathrm{CH}-+-\mathrm{CH}_{2}-\right), 2.55-2.40\left(\mathrm{~m}, 1 \mathrm{H},-\mathrm{CH}_{2}-\right), 2.34(\mathrm{~s}, 3 \mathrm{H}$, $\left.\mathrm{Ph}-\underline{\mathrm{CH}}_{3}\right), 1.28\left(\mathrm{~d}, J=6.0 \mathrm{~Hz}, 3 \mathrm{H},-\mathrm{CH}_{3}\right) ;{ }^{13} \mathrm{C} \mathrm{NMR}(50 \mathrm{MHz}, \mathrm{DMSO})$ : $\delta / \mathrm{ppm}=180.3(\mathrm{C} 2), 176.2(\mathrm{C} 5), 137.9,130.4,129.5,127.1(\mathrm{Ph}), 36.4$ (C3), 34.7 (C4), 20.9 (C8, $\left.-\mathrm{CH}_{3}\right), 16.0$ (C6).

1-Phenyl-3-methylpyrrolidine-2,5-dione $\left(4, \mathrm{C}_{11} \mathrm{H}_{11} \mathrm{NO}_{2}\right)$. Colorless solid; yield: $37 \%$; m.p.: $105-107^{\circ} \mathrm{C}\left(105-107^{\circ} \mathrm{C}\right)$ [38]; FT-IR (KBr): $v / \mathrm{cm}^{-1}=1769(\mathrm{C}=\mathrm{O}), 1702(\mathrm{C}=\mathrm{O}) ;{ }^{1} \mathrm{H}$ NMR (200 MHz, DMSO): $\delta /$ $\mathrm{ppm}=7.54-7.27(\mathrm{~m}, 5 \mathrm{H}, \quad \mathrm{N}-\mathrm{Ph}), 3.10-2.92(\mathrm{~m}, 2 \mathrm{H}$, $\left.-\mathrm{CH}-+-\mathrm{CH}_{2}-\right), 2.56-2.42\left(\mathrm{~m}, 1 \mathrm{H},-\mathrm{CH}_{2}-\right), 1.29(\mathrm{~d}, J=6.0 \mathrm{~Hz}, 3 \mathrm{H}$,
1-(4-Bromophenyl)-3-methylpyrrolidine-2,5-dione

$(6$, $\left.\mathrm{C}_{11} \mathrm{H}_{10} \mathrm{BrNO}_{2}\right)$. Colorless solid; yield: $52 \%$; m.p.: $139-141^{\circ} \mathrm{C}\left(143^{\circ} \mathrm{C}\right)$ [36]; FT-IR (KBr): $v / \mathrm{cm}^{-1}=1774(\mathrm{C}=\mathrm{O}), 1706(\mathrm{C}=\mathrm{O}) ;{ }^{1} \mathrm{H}$ NMR (200 MHz, DMSO): $\delta / \mathrm{ppm}=7.69$ (d, $J=8.0 \mathrm{~Hz}, 2 \mathrm{H}, \mathrm{N}-\mathrm{Ph}), 7.27$ (d, $J=8.0 \mathrm{~Hz}, 2 \mathrm{H}, \mathrm{N}-\mathrm{Ph}), 3.09-2.92\left(\mathrm{~m}, 2 \mathrm{H},-\mathrm{CH}-+-\mathrm{CH}_{2}-\right)$, $2.57-2.41\left(\mathrm{~m}, 1 \mathrm{H},-\mathrm{CH}_{2}-\right), 1.29\left(\mathrm{~d}, J=8.0 \mathrm{~Hz}, 3 \mathrm{H},-\mathrm{CH}_{3}\right) ;{ }^{13} \mathrm{C} \mathrm{NMR}$ (50 MHz, DMSO): $\delta / \mathrm{ppm}=179.9$ (C2), 175.9 (C5), 132.7, 131.9, 129.5 (Ph), 36.4 (C3), 34.7 (C4), 15.8 (C6).

1-(4-Iodophenyl)-3-methylpyrrolidine-2,5-dione (7, $\left.\mathrm{C}_{11} \mathrm{H}_{10} \mathrm{INO}_{2}\right)$. Colorless solid; yield: 34\%; m.p.: $149-151{ }^{\circ} \mathrm{C}$; FT-IR (KBr): $v /$ $\mathrm{cm}^{-1}=1764(\mathrm{C}=\mathrm{O}), 1704(\mathrm{C}=\mathrm{O}) ;{ }^{1} \mathrm{H}$ NMR (200 MHz, DMSO): $\delta /$ $\mathrm{ppm}=7.62(\mathrm{~d}, J=8.0 \mathrm{~Hz}, 2 \mathrm{H}, \mathrm{N}-\mathrm{Ph}), 7.41(\mathrm{~d}, J=8.0 \mathrm{~Hz}, 2 \mathrm{H}, \mathrm{N}-\mathrm{Ph})$, 3.11-2.95 (m, 2H, $\left.-\mathrm{CH}-+-\mathrm{CH}_{2}-\right)$, 2.59-2.41 (m, $\left.1 \mathrm{H},-\mathrm{CH}_{2}-\right), 1.30$ (d, $\left.J=8.0 \mathrm{~Hz}, 3 \mathrm{H},-\mathrm{CH}_{3}\right) ;{ }^{13} \mathrm{C} \mathrm{NMR}(50 \mathrm{MHz}, \mathrm{DMSO}): \delta / \mathrm{ppm}=179.9(\mathrm{C} 2)$, 175.9(C5), 134.4, 132.6, 130.8, 126.8 (Ph), 36.5(C3), 34.8 (C4), 15.8 (C6).

1-(4-Carboxyphenyl)-3-methylpyrrolidine-2,5-dione $(8$, $\mathrm{C}_{12} \mathrm{H}_{11} \mathrm{NO}_{4}$ ). Colorless solid; yield: 40\%; m.p.: 200-203 ${ }^{\circ} \mathrm{C}$; FT-IR 
$(\mathrm{KBr}): v / \mathrm{cm}^{-1}=1777(\mathrm{C}=\mathrm{O}), 1704(\mathrm{C}=0) ;{ }^{1} \mathrm{H}$ NMR $(200 \mathrm{MHz}$, DMSO): $\delta / \mathrm{ppm}=13.07(\mathrm{~s}, 1 \mathrm{H},-\mathrm{COOH}), 8.06(\mathrm{~d}, J=8.0 \mathrm{~Hz}, 2 \mathrm{H}$, $\mathrm{N}-\mathrm{Ph}), 7.44(\mathrm{~d}, J=8.0 \mathrm{~Hz}, 2 \mathrm{H}, \mathrm{N}-\mathrm{Ph}), 3.12-2.94(\mathrm{~m}, 2 \mathrm{H}$, $\left.-\mathrm{CH}-+-\mathrm{CH}_{2}-\right), 2.58-2.43\left(\mathrm{~m}, 1 \mathrm{H},-\mathrm{CH}_{2}-\right), 1,29(\mathrm{~d}, J=6.0 \mathrm{~Hz}, 3 \mathrm{H}$, $\left.-\mathrm{CH}_{3}\right) ;{ }^{13} \mathrm{C}$ NMR $(50 \mathrm{MHz}, \mathrm{DMSO}): \delta / \mathrm{ppm}=179.8$ (C2), 175.8 (C5), 167.0 (C8, -COOH), 136.8, 130.5, 130.1, 127.3 (C7), 36.5 (C3), 34.8 (C4), 15.9 (C6).

1-(4-Acethylphenyl)-3-methylpyrrolidine-2,5-dione

$\mathrm{C}_{13} \mathrm{H}_{13} \mathrm{NO}_{3}$ ). Colorless solid; yield: 47\%; m.p.: 165-167 ${ }^{\circ} \mathrm{C}$; FT-IR $(\mathrm{KBr}): v / \mathrm{cm}^{-1}=1779(\mathrm{C}=0), 1708(\mathrm{C}=\mathrm{O}) ;{ }^{1} \mathrm{H}$ NMR $(200 \mathrm{MHz}$, DMSO): $\delta / \mathrm{ppm}=8.07(\mathrm{~d}, J=8.0 \mathrm{~Hz}, 2 \mathrm{H}, \mathrm{N}-\mathrm{Ph}), 7.48(\mathrm{~d}, J=8.0 \mathrm{~Hz}$, $2 \mathrm{H}, \mathrm{N}-\mathrm{Ph}), 3.13-2.92\left(\mathrm{~m}, 2 \mathrm{H},-\mathrm{CH}-+-\mathrm{CH}_{2}-\right), 2.57-2.41(\mathrm{~m}, 1 \mathrm{H}$, $\left.-\mathrm{CH}_{2}-\right), 2.59\left(\mathrm{~s}, 3 \mathrm{H},-\mathrm{COCH}_{3}\right), 1.33\left(\mathrm{~d}, J=8.0 \mathrm{~Hz}, 3 \mathrm{H},-\mathrm{CH}_{3}\right) ;{ }^{13} \mathrm{C}$ NMR (50 MHz, DMSO): $\delta / \mathrm{ppm}=199.5\left(\mathrm{C} 8,-\mathrm{COCH}_{3}\right) 179.8(\mathrm{C} 2)$, 175.7 (C5), 141.3, 136.9, 131.1, 127.2 (Ph), 36.5 (C3), 34.8 (C4), 15.9 (C6).

1-(4-Nitrophenyl)-3-methylpyrrolidine-2,5-dione $\left.\mathrm{C}_{11} \mathrm{H}_{10} \mathrm{~N}_{2} \mathrm{O}_{4}\right)$. Yellow solid; yield: 25\%; m.p.: $158-160{ }^{\circ} \mathrm{C}$ $\left(159-161.5^{\circ} \mathrm{C}\right)$ [40]; FT-IR (KBr): $v / \mathrm{cm}^{-1}=1777(\mathrm{C}=0), 1709(\mathrm{C}=$ O); ${ }^{1} \mathrm{H}$ NMR (200 MHz, DMSO): $\delta / \mathrm{ppm}=8.36(\mathrm{~d}, J=8.0 \mathrm{~Hz}, 2 \mathrm{H}$, $\mathrm{N}-\mathrm{Ph}), 7.63(\mathrm{~d}, J=8.0 \mathrm{~Hz}, 2 \mathrm{H}, \mathrm{N}-\mathrm{Ph}), 3.18-2.96(\mathrm{~m}, 2 \mathrm{H}$, $\left.-\mathrm{CH}-+-\mathrm{CH}_{2}-\right), 2.61-2.46\left(\mathrm{~m}, 1 \mathrm{H},-\mathrm{CH}_{2}-\right), 1.31(\mathrm{~d}, J=8.0 \mathrm{~Hz}, 3 \mathrm{H}$, $\left.-\mathrm{CH}_{3}\right) ;{ }^{13} \mathrm{C}$ NMR (50 MHz, DMSO): $\delta / \mathrm{ppm}=179.6$ (C2), 175.6 (C5), 146.7, 138.6, 128.1, 124.3 (Ph), 36.5 (C3), 34.8 (C4), 15.7 (C6).

\subsection{Method of calculation}

All density functional theory (DFT) calculations were performed using the Gaussian 09 program package [41] with B3LYP [19], CAMB3LYP [20], and M06-2X [21] methods with 6-311G(d,p) basis set. The default convergence criteria were used without any constraint on the geometry. The stability of the optimized geometry was confirmed by frequency calculations, which gave real values for all the experimentally frequencies. In addition, the FineGrid (75,302)p and UltraFineGrid $(99,590)$ p grids for Euler-Maclaurin integration are used for benchmark of methods accuracy to determine the conformer's ratio. The solvent effect was introduced by the Conductor Polarizable Continuum Model (CPCM) [42].

In order to have a good description of the UV properties of the compounds, we tested the performance of TD-DFT using different types of functionals: B3LYP [19], CAM-B3LYP [20], and M06-2X [21] (i.e. hybrid GGA, hybrid with improved long-range properties and hybrid meta-GGA functionals). The functionals were used with the $6-311 \mathrm{G}(\mathrm{d}, \mathrm{p})$ basis set. UV absorption energies of all compounds were calculated for the fully optimized geometry in vacuum and ethanol as solvent.

The values of partial atomic charges from the atomic polar tenzors (APT) [31], natural population analysis (NBO) procedures [32] and charges fit to the electrostatic potential according to MerzSingh-Kollman [33], CHelp [34], and CHelpG [35] schemes are produced.

The frontier molecular orbital energies and energy gap of the investigated compounds are also calculated at the same level of DFT theory. For obtaining the chemical reactivity of the molecule, the Molecular Electrostatic Potential (MEP) surface is plotted over the optimized geometry.

The GaussView 5.0 graphical interface was used for a visual presentation of the UV spectra, molecular orbitals, and MEP [43].

\section{Conclusion}

In this work, ten 1-aryl-3-methylsuccinimides were synthesized in order to characterize and study the influence of solvents and substituents on their electronic absorptions and ${ }^{13} \mathrm{C}$ NMR spectra. A Kamlet-Taft analysis shows that most of the observed solvatochromism is due to solvent HBD acidity as compared to solvent dipolarity/polarizability (non-specific interactions). In all cases the solvent hydrogen-bond acceptor basicity has no influence on the solvatochromism. According to the Hammett correlations, better results are obtained with the $\sigma_{\mathrm{p}}^{+}$than with the $\sigma_{\mathrm{p}}$ substituent constants, indicating extensive $\pi$-electron delocalization in the aryl amide group. Much better insight into the transmission of substituent effects was obtained when the electron-donating substituents on the phenyl ring were considered separately from the electron-accepting substituents. The results obtained from UV spectroscopy measurements show that the wavenumbers of the ultraviolet absorption maxima depend significantly on the nature of the substituent on the phenyl ring, and less on the properties of the solvent. From the ${ }^{13} \mathrm{C}$ NMR chemical shifts, it can be observed that there is no significant difference in the influence of electronic effects of substituents in 4-position on the phenyl group on the $\mathrm{C} 2$ and $\mathrm{C} 5$ atoms.

A conformational analysis was carried out for the of 1-aryl-3methylsuccinimides 1-10. The performance of DFT methods using different types of functionals: B3LYP, CAM-B3LYP, and M06-2X with the $6-311 G(d, p)$ basis set, are tested for prediction of the accurate energy and ratio of conformers, as well as the properties derived from them.

Special attention is directed towards an accurate prediction of the UV absorption. The best correlation is provided between experimental and calculated maxima from TD calculations with B3LYP method in vacuum. The CAM-B3LYP and M06-2X methods highly underestimate the values of UV maxima but still produce good correlation results. This result is in agreement with the fact that for small and rigid molecules the B3LYP method produces more accurate results than other functionals. The solvent influence on the correlation results is detectable but it is relatively small, compared to the theory-experiment discrepancies. The influence of the integration grid on the quality of produced results is tested and shows small but positive impacts. Only the results from M06-2X method in solvent shows big benefit from applying a tighter integration grid. The impact of values simulated based on the static or dynamic results is relatively small but it is directly connected with the introduction of solvent effects.

Excellent relations between experimental and theoretical data directly indicate a high validity and precision of the proposed models.

\section{Acknowledgments}

This work has been financially supported by the Ministry of Education, Science and Technological Development of the Republic of Serbia, under Grants no. 172013 and 172035. Numerical simulations were run on the PARADOX cluster at the Scientific Computing Laboratory of the Institute of Physics Belgrade, supported in part by the Ministry of Education, Science and Technological Development of the Republic of Serbia under project No. ON171017.

\section{Appendix A. Supplementary data}

Supplementary data related to this article can be found at http:// dx.doi.org/10.1016/j.molstruc.2016.09.086.

\section{References}

[1] J. Obniska, A. Zejc, J. Karolak-Wojciechowska, Farmaco 54 (1999) 423-429.

[2] N. Perišić Janjić, R. Kaliszan, P. Wiczling, N. Milošević, G. Ušćumlić, N. Banjac, Mol. Pharm. 8 (2011) 555-583.

[3] R.A. Katritzky, K.S. Nair, M.R. Witeck, M.S. Hutchins, Arkivoc (2003), 9-18 (Issue in Honor of Prof. Gábor Bernáth).

[4] H.J. Poupaert, D. Vandervorst, P. Guiot, M.M.M. Moustafa, P.P. Dumont, J. Med. 
Chem. 27 (1984) 76-78.

[5] N. Trišović, N. Valentić, G. Ušćumlić, Chem. Cent. J. 5 (2011) 62-63.

[6] N.R. Banjac, N.P. Trišović, Vitnik VD. Vitnik ŽJ, N.V. Valentić, G.S. Ušćumlić, I.O. Juranić, Monatsh. Chem. 144 (2013) 1525-1535.

[7] K. Kamiński, J. Obniska, Bioorg. Med. Chem. 16 (2008) 4921-4931.

[8] J. Obniska, H. Byrtus, K. Kamiński, M. Pawłowski, M. Szczesio, J. KarolakWojciechowska, Bioorg. Med. Chem. 18 (2010) 6134-6142.

[9] K. Kamiński, S. Rzepka, J. Obniska, Bioorg. Med. Chem. Lett. 21 (2011) 5800-5803.

[10] N. Perišić Janjić, R. Kaliszan, N. Milošević, G. Ušćumlić, N. Banjac, J. Pharm. Biomed. 72 (2013) 65-73.

[11] J.S. Murray, F. Abu-Awwad, P. Polityer, L.C. Wilson, A.S. Troupin, R.E. Wall, Int. J. Quant. Chem. 70 (1998) 1137-1143.

[12] C. Hansch, J.P. Björkrotahn, A. Leo, J. Pharm. Sci. 76 (1987) 663-687.

[13] D. Hadjipavlou-Litina, Med. Res. Rev. 18 (1998) 91-119.

[14] M.J. Kamlet, J.L.M. Abboud, M.H. Abraham, R.W. Taft, J. Org. Chem. 48 (1983) 2877-2887.

[15] L. Hammett, J. Am. Chem. Soc. 59 (1937) 96-103.

[16] M. Kamlet, J. Abboud, R. Taft, Prog. Phys. Org. Chem. 13 (1981) 485-630.

[17] H. Brown, Y. Okamoto, J. Am. Chem. Soc. 80 (1958) 4979-4987.

[18] M. Charton, Prog. Phys. Org. Chem. 13 (1981) 119-251.

[19] A.D. Becke, J. Chem. Phys. 98 (1993) 5648-5652.

[20] T. Yanai, D. Tew, N. Handy, Chem. Phys. Lett. 393 (2004) 51-57.

[21] Y. Zhao, D.G. Truhlar, Theor. Chem. Acc. 120 (2008) 215-241.

[22] S.E. Wheeler, K.N. Houk, J. Chem. Theory. Comput. 6 (2010) 395-404.

[23] T. Mori, Y. Inoue, S. Grimme, J. Phys. Chem. A 111 (2007) 4222-4234.

[24] A. Charaf-Eddin, A. Planchat, B. Mennucci, C. Adamo, D. Jacquemin, J. Chem. Theory. Comput. 9 (2013) 2749-2760.

[25] R. Brasca, M.A. Romero, H.C. Goicoechea, A.M. Kelterer, W.M.F. Fabian, Spectrochim. Acta A 115 (2013) 250-258.

[26] V.M. Arsovski, B.Đ. Božićn, J.M. Mirković, V.D. Vitnik, Ž.J. Vitnik, W.M.F. Fabian, S.D. Petrović, D.Ž. Mijin, J. Mol. Model. 20 (2014) 2384.

[27] T. De Meyer, K. Hemelsoet, L. Van der Schueren, E. Pauwels, K. De Clerck, V. Van Speybroeck, Chem. Eur. J. 18 (2012) 8120-8129.
[28] T. Etienne, T. Very, E.A. Perpète, A. Monari, X. Assfeld, J. Phys. Chem. B 117 (2013) 4973-4980.

[29] G. Uray, U.G. Wagner, W.M.F. Fabian, Comp. Theor. Chem. 977 (2011) $103-110$.

[30] V.D. Vitnik, Ž.J. Vitnik, Spectrochim. Acta A 138 (2015) 1-12.

[31] J. Cioslowski, J. Am. Chem. Soc. 111 (1989) 8333-8336.

[32] A.E. Reed, F. Weinhold, J. Chem. Phys. 78 (1983) 4066-4073.

[33] U.C. Singh, P.A. Kollman, J. Comp. Chem. 5 (1984) 129-145.

[34] L.E. Chirlian, M.M. Francl, J. Comp. Chem. 8 (1987) 894-905.

[35] C.M. Breneman, K.B. Wiberg, J. Comp. Chem. 11 (1990) 361-373.

[36] E. Dane, O. Blacke, H. Hemmel, F. Müller, Liebigs Ann. Chem. 607 (1957) $92-108$.

37] G.Q Li, Y. Li, L.X. Dai, S.L. You, Org. Lett. 9 (2007) 3519-3521.

[38] E. Bellack, J.B. De Witt, J. Agric. Food. Chem. 2 (1954) 1176-1179.

[39] K.F. Hebeubrock, Liebigs Ann. Chem. 1978 (1978) 320-336.

40] Sumimoto Chemical Co. Ltd. (1971) GE Pat No 2,100,800.

[41] M.J. Frisch, G.W. Trucks, H.B. Schlegel, G.E. Scuseria, M.A. Robb, J.R. Cheeseman, G. Scalmani, V. Barone, B. Mennucci, G.A. Petersson, H. Nakatsuji, M. Caricato, X. Li, H.P. Hratchian, A.F. Izmaylov, J. Bloino, G. Zheng, J.L Sonnenberg, M. Hada, M. Ehara, K. Toyota, R Fukuda, J. Hasegawa, M. Ishida, T. Nakajima, Y. Honda, O. Kitao, H. Nakai, T. Vreven, J.A. Montgomery, J.E. Peralta, F. Ogliaro, M. Bearpark, J.J. Heyd, E. Brothers K.N. Kudin, V.N. Staroverov, T. Keith, R. Kobayashi, J. Normand, K. Raghavachari, A. Rendell, J.C. Burant, S.S. Iyengar, J. Tomasi, M. Cossi, N. Rega, J.M. Millam, M. Klene, J.E. Knox, J.B. Cross, V. Bakken, C. Adamo, J. Jaramillo, R. Gomperts, R.E. Stratmann, O. Yazyev, A.J. Austin, R. Cammi, C. Pomelli, J.W. Ochterski, R.L. Martin, K. Morokuma, V.G. Zakrzewski, G.A. Voth, P. Salvador, J.J. Dannenberg, S. Dapprich, A.D. Daniels, O. Farkas, J.B. Foresman, J.V. Ortiz, J. Cioslowski, D.J. Fox, Gaussian 09, Revision C.01 Gaussian, Inc., Wallingford, 2010.

[42] M. Cossi, N. Rega, G. Scalmani, V. Barone, J. Comput. Chem. 24 (2003) 669-681.

[43] R. Dennington, T. Keith, J. Millam, GaussView, Version 5.0.9, Semichem Inc Shawnee Mission, KS, 2009. 